Usage, Usability, and Utility of 3D City Models, 03005 (2012)

DOI: $10.1051 / 3 \mathrm{u} 3 \mathrm{~d} / 201203005$

(c) Owned by the authors, published by EDP Sciences, 2012

\title{
Preliminary investigations into the potential of improving rendering performance of 3D datasets using 2D generalisation
}

\author{
C. Ellul ${ }^{1}$ and J.A. Joubran ${ }^{2}$ \\ ${ }^{1}$ Dept. of Civil, Environmental and Geomatic Engineering, UCL, London WC1E 6BT, UK \\ ${ }^{2}$ Department of Civil Engineering (Geodesy), Technical-Israel Institute, Haifa 32000, Israel
}

\begin{abstract}
Three dimensional (3D) city models have many uses including city walk-throughs or fly-throughs to show what a new building would look like in situ, or whether a view or light will be blocked by a new structure, flood and signal modelling. Often, these models are created using a process of extrusion of detailed 2D topographic mapping. The resulting 3D datasets contain many thousands of polyhedra, which in turn results in performance issues when attempting to visualize such models in Google Earth. To address this issue we first generalise the 2D dataset (using simplification and aggregation) and then extrude the generalised 2D maps to 3D, comparing the rendering performance and visual aspects of the resulting datasets.
\end{abstract}

\section{INTRODUCTION}

Three-dimensional (3D) City Models are becoming more prevalent and have applications including utility infrastructure validation ("call-before-you-dig"), planning [2, 7, 16] and augmented reality [5]. The process of extrusion ("growing" the 2D data to a given height) is an efficient method of creating a 3D dataset when a larger area is to be covered (for example an entire city), and where high levels of detail (e.g. sloping roofs) are not required. It also has the advantage of integrating 3D buildings with a 2D footprint [20], resulting in Level of Detail 1 (LoD1) buildings [22]. However, such models are generally complex with respect to individual components and the required rendering resources [13]. Indeed, the resulting 3D data is generally quite large in volume, and thus potentially difficult to visualize in its entirety utilizing 3D packages such as ArcGlobe [9] or Google Earth [14].

This paper provides a preliminary investigation into the impact of $2 \mathrm{D}$ generalisation carried out prior to extrusion. We first simplify and aggregate a detailed 2D topographic dataset and then extrude the resulting polygons to an average height for each block, comparing this with directly extruding the detailed 2D building objects and removing internal walls. The main focus on improving rendering performance and a brief comparison is also made of the resulting visual appearance of the dataset.

\section{GENERALISATION}

A number of approaches can be identified to reducing the volume of data to be rendered for 3D City Model, including data compression [32] and mesh simplification [27]. The concept of Levels of Detail (LoD) [22] where different representations of the data is used at different scales, can also be used to limit the size of datasets - indeed the effective visualization of complex 3D City Models requires an

This is an Open Access article distributed under the terms of the Creative Commons Attribution License 2.0, which permits unrestricted use, distribution, and reproduction in any medium, provided the original work is properly cited. 


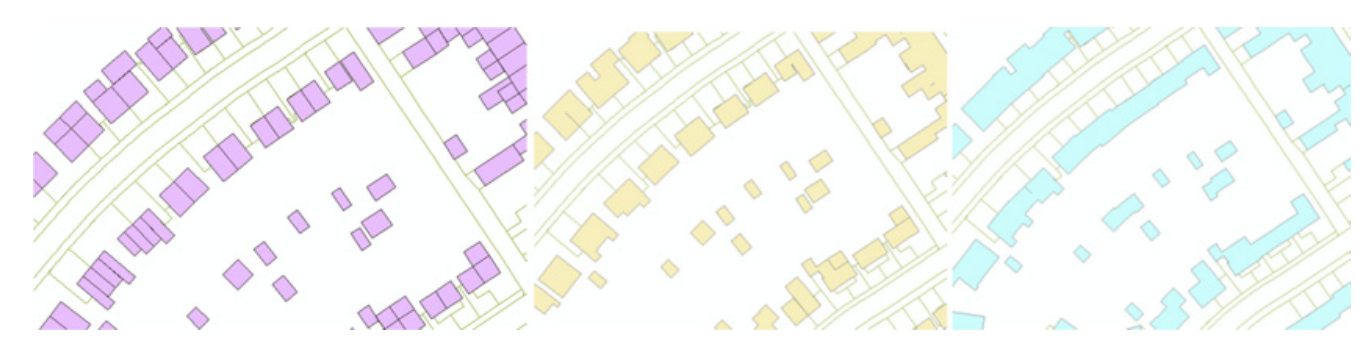

Figure 1. Pettswood data simplified using a $5 \mathrm{~m}$ tolerance (left). Data aggregated using a $1 \mathrm{~m}$ tolerance (centre) and aggregation using a $5 \mathrm{~m}$ tolerance (right).

abstraction of City Model components [13]. As [23] note a "In the interests of compressing data, it is often necessary to remove detail, fitting them into a storage device of limited capacity, processing them faster or creating less confusing visualizations that emphasize general trends".

Generalisation thus derives a map or dataset with reduced complexity and contents from a detailed spatial data source, while retaining the major semantic and structural characteristics of the source data. Steps include: classification (grouping features according to their type); simplification (removing points to create a simpler shape according to an algorithm such as that developed by Douglas-Peucker1973 (cited in [23]); aggregation (replacement of several polygons by a single polygon [10]); exaggeration (to highlight important features in a map [24]); symbolization (replacing features with point symbols); induction (which infers relationships between features) [18, 24, 26]. Algorithms are generally mature in a 2D context [21, 28, 29, 31, 33] and are embedded in commercial software. Work has also been carried out on 3D generalisation $[1,12,13,15,16,19,20]$.

\section{METHODOLOGY}

The dataset used for our experiments is a detailed topographic mapping dataset ${ }^{1}$ for a suburb in the South East of London (Pettswood). The $2 \mathrm{~km}$ by $2 \mathrm{~km}$ dataset includes height information for each building polygon (see [8]). For convenience, and given that the primary interest at this stage is the potential improvement in rendering performance rather than task-specific generalisation or the visual output, ESRI's ArcMap software [10] is used for generalisation.

\subsection{Generalizing (simplifying and aggregating) and extruding the data}

The first stage of our generalisation process involved the removal of any building features with a total area of less than $25 \mathrm{~m}^{2}$. This stage was followed by a simplification process using a tolerance of $5 \mathrm{~m}$, and then by an aggregation process using a $1 \mathrm{~m}$ and $5 \mathrm{~m}$ tolerance (Figure 1 below). The average height of the resulting building blocks was calculated by a weighted average height according to the areas of the aggregated blocks.

Oracle Spatial [24] was used to extrude both the original and the generalised datasets (see [8]) and GoLoader software [30] used to load the data. For the detailed dataset, the shared interior walls resulting from the extrusion process were removed [8] leaving the outer shell. For the generalised datasets, a number of invalid polygons caused by the displacement, reshaping and resizing operations [18] could not be extruded ( 23 for the $5 \mathrm{~m}$ aggregation, 103 for the $1 \mathrm{~m}$ dataset) and were removed.

\footnotetext{
${ }^{1}$ UKMap, from The GeoInformation Group, www.geoinformationgroup.co.uk
} 
Table 1. Results of the generalisation and extrusion process.

\begin{tabular}{|l|l|l|l|l|}
\hline & \# Polygons (2D) & Area $\left.\mathbf{( m}^{2}\right)$ & Volume $\left.\mathbf{( m}^{3}\right)$ & \# Faces (3D) \\
\hline Original data & 12757 & 413273.34 & 3055072.32 & 76622 (inner walls removed) \\
\hline$<25 \mathrm{~m}^{2}$ area deleted & 5819 & 341745.83 & 2749486.86 & N/A \\
\hline Simplified data $(5 \mathrm{~m})$ & 5819 & 345070.01 & 2773196.98 & N/A \\
\hline Aggregated data (1 m) & 2491 & 342630.71 & 2756731.06 & 24992 \\
\hline Aggregated data (5 m) & 1113 & 384964.48 & 3099044.63 & 20913 \\
\hline
\end{tabular}

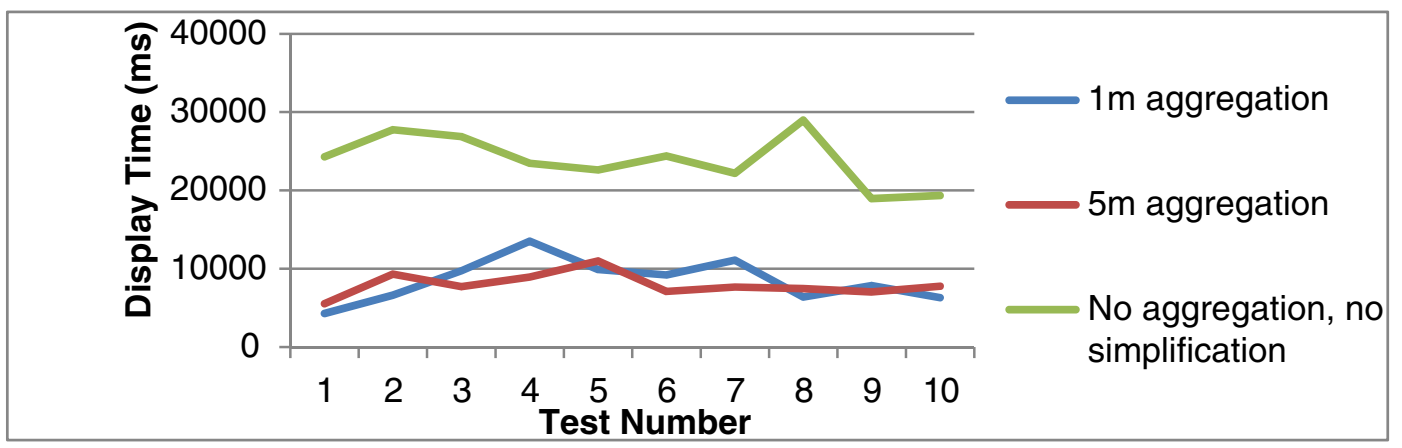

Figure 2. Rendering performance of the generalised and extruded datasets.

\subsection{The resulting datasets}

Table 1 highlights the changes resulting from the generalisation process, additionally listing the number of Faces that result from the extrusion process. As can be seen, the number of building polygons is reduced significantly by aggregation. It can also be noted that aggregation, in particular using a $5 \mathrm{~m}$ tolerance, results in a significant increase in the total building area.

\subsection{Visualisation and performance testing}

ArcGlobe, part of ESRI's ArcGIS suite [9] was used visualise the results of the generalisation and extrusion processes. A browser-embedded Google Earth plug-in [14] was used for performance testing, with the browser restarted for each test to ensure that the cache was cleared. A test script was written that tracked the time to display the datasets and as Google Earth displays a series of 'base' images underpinning any other data each KML file was set to fly to an identical location on start-up, ensuring that identical image sets were loaded. Each test (1 $\mathrm{m}$ aggregation, $5 \mathrm{~m}$ aggregation and no aggregation) was run 10 times, for a total of 30 test runs.

\section{RESULTS}

\subsection{Performance}

Figure 2 below shows the resulting time to render the three datasets ${ }^{2}$. The overall aim of this process is to reduce the number of Faces that are passed to the rendering pipeline [5] and hence the number

\footnotetext{
${ }^{2}$ Note that the loading time - i.e. the time taken to download the data from the web server and prepare it for rendering - was measured separately and is not included in the above results.
} 


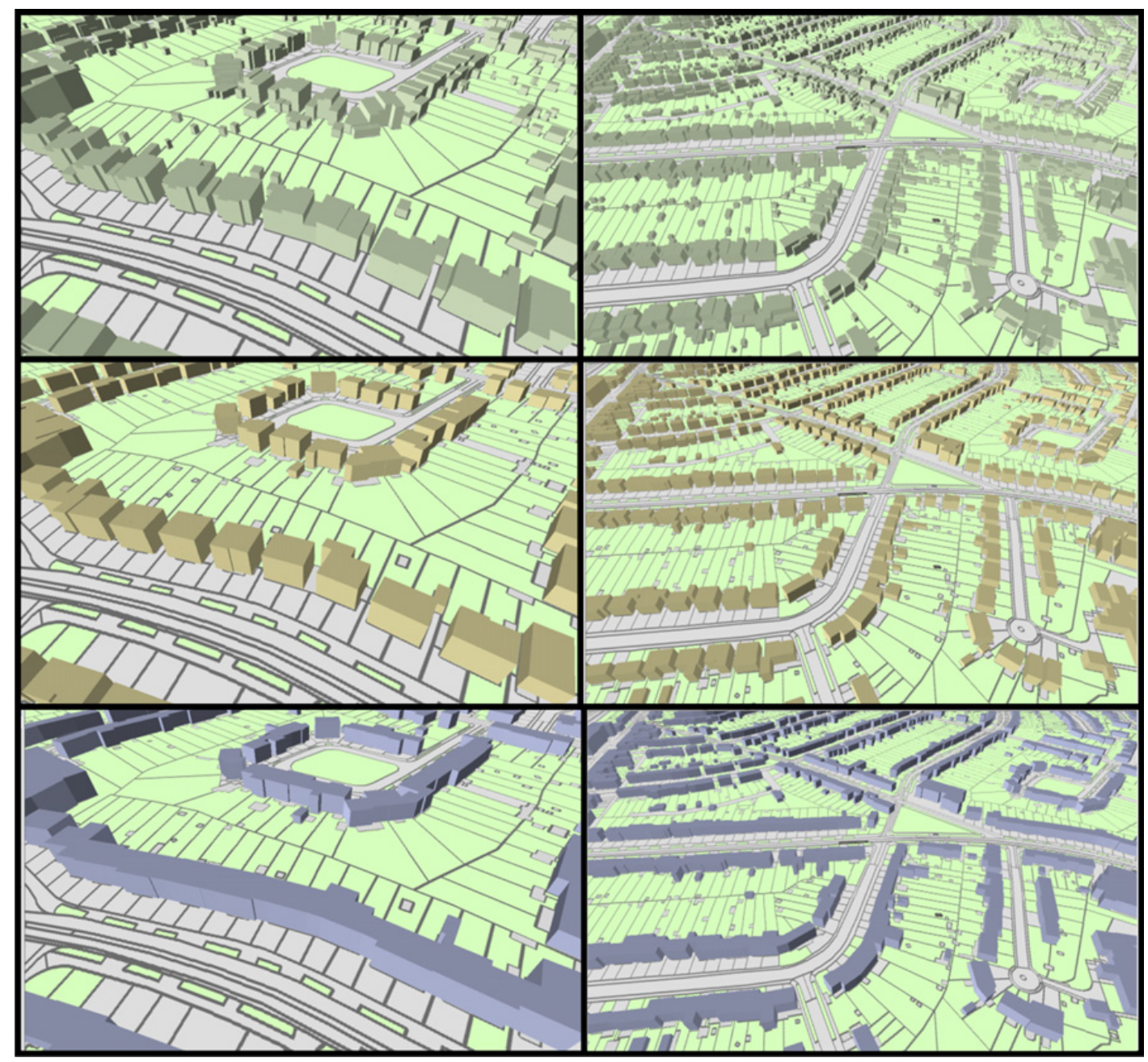

Figure 3. Visual appearance of aggregated datasets - no aggregation or simplification (top), $5 \mathrm{~m}$ simplification and $1 \mathrm{~m}$ aggregation (middle) and $5 \mathrm{~m}$ simplification and $5 \mathrm{~m}$ aggregation (bottom).

of Faces input to any visibility pre-computation or clipping. This reduces the overall computational load for the rendering process. The generalisation process results in a significant reduction in rendering performance time, with the un-generalised dataset taking an average of $23,885 \mathrm{~ms}$ to render, the $5 \mathrm{~m}$ aggregation taking 7,948 $\mathrm{ms}$ on average and the $1 \mathrm{~m}$ aggregation taking 8,486 ms. The similarity of results for the aggregated datasets reflects the similar number of Faces.

\subsection{Visual appearance}

Figure 3 shows the resulting 3D maps for the disaggregated (top), $1 \mathrm{~m}$ aggregated (middle) and $5 \mathrm{~m}$ aggregated (bottom) datasets. As can be seen, a significant loss of detail occurs for the $5 \mathrm{~m}$ aggregation when compared to the original dataset - both in relation to building outline and importantly to the gaps between the various buildings. There is also loss of detail in terms of height variation and building outline detail between the disaggregated data and the $1 \mathrm{~m}$ aggregation, although the generalisation 
process has not resulted in loss of significant features or the general sense of the neighbourhood being constructed of small blocks with spaces in between.

Considering these results in the light of the very similar performance results obtained for both $1 \mathrm{~m}$ and $5 \mathrm{~m}$ aggregation, it is suggested that a $1 \mathrm{~m}$ aggregation (along with the $5 \mathrm{~m}$ simplification) may yield relatively optimal results in terms of performance, without too much loss of visual detail in the resulting map.

\section{DISCUSSION AND CONCLUSION}

The results obtained show that there are significant performance gains to be obtained by applying a process of 2D generalisation prior to extruding a dataset into a 3D City Model. Although some detail is lost in terms of the model, the performance improvement resulting in a rendering process 2.8 times faster than the original highlights the potential of this approach; in particular as overall the major semantic and structural characteristics of the source data are retained.

The ability to rapidly display large 3D models is particularly important when considering applications of $3 \mathrm{D}$ city models. Unlike in the $2 \mathrm{D}$ case, where there is a smooth transition between scales and all data is represented at a level appropriate for the scale in question, in the 3D case a mixedscale (or level of detail) representation is more appropriate for applications such as urban planning $[2,7,16]$ or navigation [3, 4]. Specifically, the user is interested in a high level of detail for their immediate surroundings, but less detail further away. The equivalent $2 \mathrm{D}$ generalisation concept is that of 'exaggeration' - where important features are given prominence on an otherwise generalised map, and the generalisation methods shown here could therefore be applied to improve the rending performance of the more distant data elements.

To show the potential of using 2D generalisation to improve $3 \mathrm{D}$ rendering, we have utilised a standard out-of-the box generalisation process. This does not take into account the fact that generalisation is very much context/task specific and that different settings are appropriate for different uses. Further investigation into the requirements for context-specific generalisation of 3D datasets, and whether the method described above could meet these needs, is required, along with comparison with the outcome when using 3D generalisation directly. Performance tests should also be extended to more urban datasets, where there are continual blocks of buildings down the street, and the results tested for sensitivity to the smoothing and aggregation tolerances used.

In conclusion, while improving performance is a relatively straightforward issue with easily quantifiable results, providing users of 3D City Models with appropriate content and detail for the task at hand is perhaps more difficult due to the varying nature of uses of such models. The importance understanding what is cognitively useful within a City Model should not be underestimated.

The authors would like to thank the GeoInformation Group for the provision of the UK Map dataset. Thanks also go to the team at Snowflake Ltd. for the GoLoader software.

\section{References}

[1] Baig S, Abdul-Rhaman A, 2012 (forthcoming), Generalization and Visualization of 3D Building Models in City GML in: Pouliot, J, Daniel, S, Hubert, F and Zamyadi, A, Progress and New Trends in 3D Geoinformation Sciences, Springer.

[2] Batty M, Chapman D, Evans S, Haklay M, Keupers S, Shiode N, Hudson Smith A, Torrens P, 2001, Visualising the City: Communicating Urban Design to Planners and Decision-makers, in Brail R, Klosterman R (eds) Planning Support Systems, Models and Visualisation Tools (405443). ESRI Press and Center Urban Policy Research, Rutgers University: Redland. 
Usage, Usability, and Utility of 3D City Models

[3] Blechschmied H, Coors V, Etz M, 2006, Augmented Reality and Location-Based Services Projects in Zlatanova S, Prosperi D (eds), Large-scale 3D data integration:challenges and opportunities, Taylor and Francis.

[4] Boguslawski P, Gold C, Ledoux H, 2011, Modelling and Analysing 3D Buildings with a Primal/Dual data structure, ISPRS Journal of Photogrammetry and Remote Sensing, 66, 188-197.

[5] Chen J, Chen C, 2008, Foundations of 3D Graphics Programming: Using JOGL and Java3D, 2nd Edition, Springer Publishing Company, ISBN: 9781848002838.

[6] Coors V, 2004, 3D Modelling and Visualisation, Computers \& Graphics, 28:4, 519-526.

[7] Coors V, Hunlich K, On G, 2009, Constraint-based Generation and Visualization of 3D City Models, in Lee J, Zlatanova S (eds) 3D GeoInformation Sciences, Springer Berlin Heidelberg.

[8] Ellul, C, 2012 (forthcoming), Can Topological Pre-Culling of Faces Improve Rendering Performance of City Models in Google Earth, in: Pouliot, J, Daniel, S, Hubert, F and Zamyadi, A, Progress and New Trends in 3D Geoinformation Sciences, Springer.

[9] ESRI 2011, ArcGlobe [online] Available from: http://www.esri.com/software/arcgis/extensions/ 3danalyst/index.html [Accessed 12th January 2012].

[10] ESRI 2012, Aggregating Polygons (Data Management) [online] Available from: http:// resources.esri.com/help/9.3/arcgisengine/java/gp_toolref/data_management_ tools/aggregate_polygons_data_management_.htm [Accessed 23rd June 2012].

[11] ESRI ArcMap 2012 - ArcGIS for Desktop [online] Available from: http://www.esri.com/ software/arcgis/arcgis-for-desktop/features.html\#spatial-analysis_panel

[12] Fan H, Meng, L, Jahnke M, 2009, Generalization of 3D Buildings Modelled by CityGML, in Cartwright W, Gartner G, Meng L, Peterson M (eds) Lecture Notes in Geoinformation and Cartography, Springer Berlin Heidelberg, 2009.

[13] Glander T, Dollner J, 2008, Techniques for Generalizing Building Geometry of Complex Virtual 3D City Models in: Van Oosterom P, Zlatanova S, Penninga F, Fendel E (eds) Advances in 3D GeoInformation Systems, Springer.

[14] Google Earth 2012 - 3D Buildings Showcase [online] Available from: http://www.google.co.uk/ intl/en_uk/earth/explore/showcase/3dbuildings.html [Accessed 12th January 2012].

[15] Guercke R, Brenner C, Sester M, 2009, Generalization of Semantically Enhanced 3d City Models, Proceedings of the GeoWeb 2009 Conference, Vancouver, Canada.

[16] He S, Moreau G, Martin J-Y, 2012, Footprint-Based 3D Generalization of Building Groups for Virtual City Visualization, The Fourth International Conference on Advanced Geographic Information Systems, Applications, and Services, Valencia, Spain [online] Available from: http://www.thinkmind.org/index.php?view=article\&articleid=geoprocessing_2012_6_30_30187 [Accessed 22 $2^{\text {nd }}$ July 2012].

[17] Isikdag U, Zlatanova S, 2010, Interactive modelling of buildings in Google Earth: A 3D tool for Urban Planning, in Neutens T, De Maeyer P (eds.) Developments in 3D Geo-Information Sciences, Springer 2010, 52-70.

[18] Joubran, A.J., Doytsher, Y., 2010. "Pseudo-Physical Approach for Automated Urban Maps Generalization". COM.Geo 2010, 1st International Conference on Computing for Geospatial Research \& Applications, Washington DC, USA.

[19] Kada M, 2007, A Contribution to 3D Generalisation, Photogrammetric Week, 41-51.

[20] Kada, M, 2009, The 3D Berlin Project, Photogrammetric Week, 331-340.

[21] Kilpelainen, T., 2000. "Knowledge Acquisition for Generalization Rules". Cartography and Geographical Information System, Vol. 27, No. 1, pp. 41-50.

[22] Kolbe T, Groger G, Plumer L, 2005, CityGML - Interoperable Access to 3D City Models - in van Oosterom P, Fendel E, Zlatanova S (eds) Proceedings of the International Symposium on Geo-Information for Disaster Management, Delft, Springer Verlag.

[23] Longley P, Goodchild M, Maguire D, Rhind D, 2011, Geographical Information Systems and Science Third Edition. Hoboken, NJ: Wiley. 
[24] McMaster, R. B. and K.S. Shea., 1992.Generalization in digital cartography. Association of American Geographers, Washington, DC.

[25] Oracle 2011 - Oracle Spatial SDO_UTIL.EXTRUDE [online] Available from: http://docs. oracle.com/cd/B28359_01/appdev.111/b28400/sdo_util.htm\#BJECJIIE [Accessed $12^{\text {th } \text { January }}$ 2012].

[26] Robinson A, Morrison J, Muehrcke P, Kimerling J, Guptill A, 1995, Elements of Cartography, Wiley and Sons.

[27] Sester M, 2007, 3D Visualization and Generalization. 51st Photogrammetric Week, Stuttgart Germany, 285-295.

[28] Sester, M., 2005. "Optimization Approaches for Generalization and data Abstraction". International Journal of Geographical Information Science, Vol. 19, No. 8-9, pp. 871-897.

[29] Sester, M., Burrener, C., 2005. "Continuous Generalization for Visualization on Small Mobile Devices". Proc. Conference on Spatial Data Handling -Springer, pp. 355-368.

[30] Snowflake 2012, Go Loader - Load GML Into your Database of Choice [online] Available from http://www.snowflakesoftware.com/products/goloader/ [Accessed 21st January 2012].

[31] Stieniger, S., Weibel, R., 2007. "Relations among Map Objects in Cartographic Generalization". Cartography and Geographic Information Science, Issue 34 (3), pp. 175-179.

[32] Van Essen R, 2008, Maps Get Real: Digital Maps Evolving from Mathematical Line Graphs to Virtual Reality Models, in van Oosterom P, Zlatanova S, Penninga F, Fendel E (eds) Advances in 3D GeoInformation Systems, Springer.

[33] Weibel, R., Jones, C. B., 1998. "Computational Perspective on Map Generalization.", GeoInformatica, Vol. 2, No. 4, pp: 307-314. 